\title{
Evaluation of ocular trauma related to falling in elderly patients
}

\author{
Avaliação dos traumas oculares relacionados \\ à queda da própria altura em idosos
}

Daniel Zaide Spritzer ${ }^{1}$, Leonardo Mancini Volpini ${ }^{1}$, João Henrique Cardoso Meireles da Costa ${ }^{1}$, Morizot Leite Filho ${ }^{1}$

\begin{abstract}
Objective: Evaluate ocular trauma cases related to falling in elderly patients e compare the prevalence and severity of the cases. Methods: A series of cases was made with 52 patients aging 60 or more within the period of 36 months presenting ocular trauma related to falling, whereas the prevalence between the gender, the need for hospitalization or surgery and subsequent visual deficit were evaluated, as well as the severity of the cases. Results: Thirty-three (63.5\%) of 52 patients were from the female gender, over which $30.3 \%$ had need for surgery and $18.2 \%$ developed visual deficit and 19 (36.5\%) were from the male gender where $42.1 \%$ needed surgery and $26.3 \%$ developed visual deficit. Conclusion: The study has shown a higher prevalence of cases in the female gender, although the severity was higher in the male gender.
\end{abstract}

Keywords: Ocular trauma; Accidental falls; Aged; Risk factors

\section{RESUMO}

Objetivo: Avaliar casos de trauma ocular relacionados à queda da própria altura em idosos e comparar a prevalência e gravidade dos atendimentos. Métodos: Foi realizado uma série de casos em 52 pacientes com 60 anos ou mais dentro do período de 36 meses, compreendido entre janeiro de 2012 a dezembro de 2014, com história de trauma ocular relacionado à queda da própria altura, onde foi avaliada a prevalência conforme o sexo, necessidade de internação e de cirurgia, sequela visual e a gravidade dos casos. Resultados: Trinta e três $(63,5 \%)$ dos 52 pacientes eram do sexo feminino, sendo 30,3\% desses com necessidade cirúrgica e $18,2 \%$ com sequelas visuais, outros 19 (36,5\%) eram do sexo masculino, sendo 42,1\% desses com necessidade cirúrgica e 26,3\% com sequelas visuais. Conclusão: Foi mais prevalente o atendimento de casos de trauma ocular relacionado à queda da própria altura em mulheres, mas a gravidade dos atendimentos foi maior nos homens.

Descritores: Trauma ocular; Acidentes por queda; Idoso; Fatores de risco

'Oftalmologia da Policlínica de Botafogo - Rio de Janeiro, RJ, Brazil. Study conducted at the Emergency Unit of Policlínica de Botafogo. The authors declare no conflicts of interests.

Received for publication 11/03/2015 - Accepted for publication 27/10/2015 


\section{INTRODUCTION}

$\mathbf{F}$ alls from standing height are an event requiring a lot of attention due to the risk of severe injuries in different parts of the human body.

The elderly should be assessed under specific aspects, and it is due to various risk factors inherent to their physical conditions and environmental factors.

Among the parts of the body affected in this type of trauma is the face, in which ocular trauma is included.

It is estimated that the cost of injuries related to falls in individuals over 65 years in the US were U\$ 12.6 billion. This amount increased significantly with the increase of hospital costs and expansion of the geriatric population. ${ }^{(1)}$

The incidence of falls increases with age and varies according to the lifestyle. About 30 to $40 \%$ of people over 65 years suffer one fall every year, reaching $50 \%$ of those aged 80 years or more. . $^{(2,3)}$

Falls are equally common in men and women, yet there is a greater tendency for injuries in women. ${ }^{(4)}$

About $60 \%$ of those with history of falls will suffer it again the following year. ${ }^{(5)}$

Approximately $5 \%$ of falls in elderly will result in hospitalization. ${ }^{(6)}$

\section{Methods}

In the emergency sector of the Ophthalmology Service at the Polyclinic of Botafogo a study was conducted on a series of cases in which 52 cases of ocular trauma arising from falling from standing height were assessed in people aged 60 years and older during the period from January 2012 to December 2014.

The frequency was compared between male and female victims, and ocular manifestations were assessed as for the need for hospitalization for reconstructive surgery and permanent sequelae in vision.

Surgical need is understood from eyebrow suture to eviscerated eyeball, and visual sequelae is any level of reduced visual acuity.

The number of cases in which surgery was necessary and visual sequelae were developed was also assessed.

\section{RESULTS}

A significantly higher prevalence of cases in women than in men was found, being 33 and 19 , respectively. That is, about $63.5 \%$ of women and $36.5 \%$ of men of the amount assessed, represented in Figure 1.

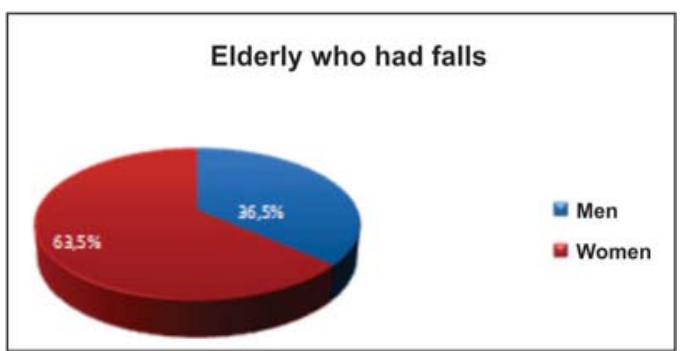

Figure 1: Percentage of falls between the sexes
Nine hospitalizations were necessary, being all of them surgical and with visual sequelae, as shown in figure 2.

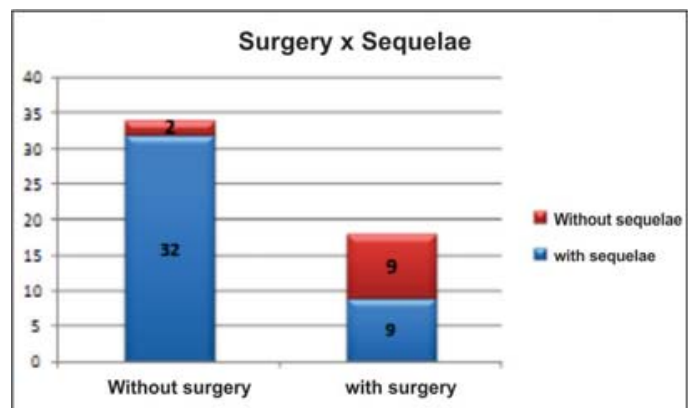

Figure 2: Comparison between the frequency of sequelae in surgical and non-surgical cases.

There were visual sequelae in 11 cases of fall from standing height, in which 5 were men and 6 were women, represented in Figure 3.

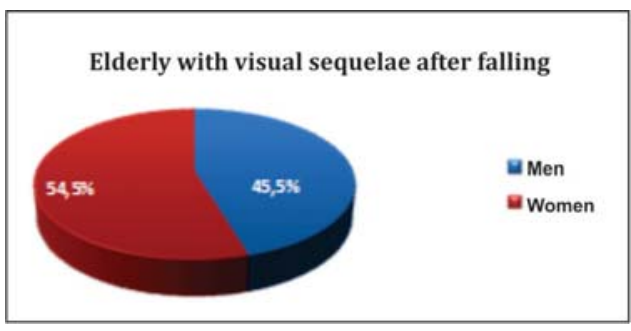

Figure 3: Percentage of sequelae among the cases in men and women.

Of the 52 cases, in 18 surgical measures were necessary, being 8 in men and 10 in women, half of the cases resulting in visual sequelae, as observed in Figure 4.

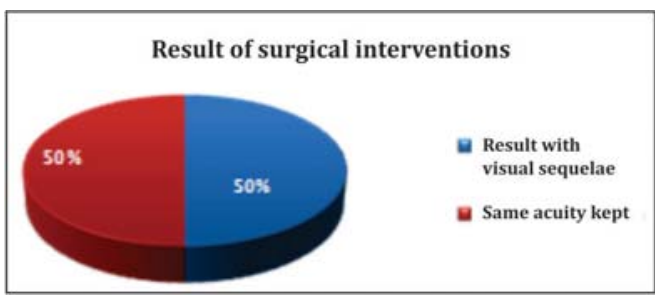

Figure 4: Percentage of sequelae among surgical patients.

In $30.3 \%$ of ocular trauma cases in fall from standing height that occurred in women surgery was necessary, whereas in men this percentage was $42.1 \%$, illustrated in Figure 5.

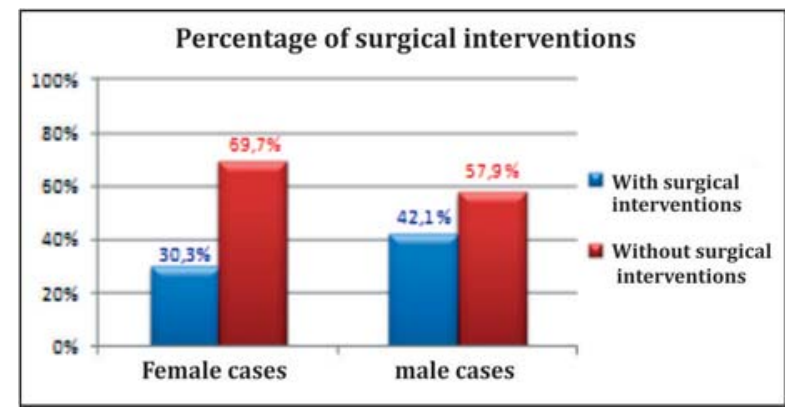

Figure 5: Comparison between the percentage of surgical need in men and women. 
In $26.3 \%$ of cases that occurred in male people there was visual sequelae; in women this percentage was $18.1 \%$, represented in Figure 6

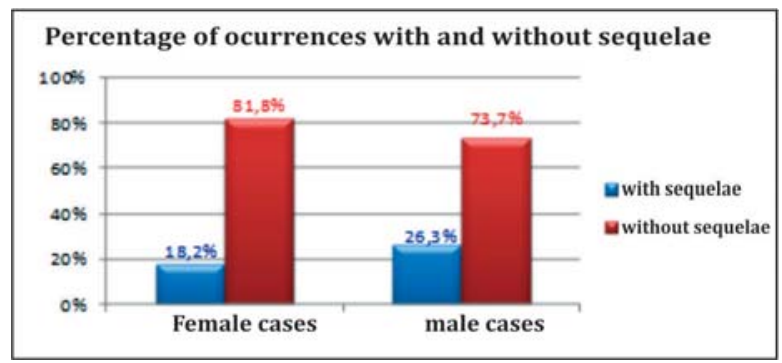

Figure 6: Comparison between the percentage of visual sequelae in men and women.

The severity of cases varied greatly, being very frequent the periorbital hematoma and the conjunctival haemorrhage. The frequency of corneal laceration and orbital fractures called our attention, as it can be seen in Table 1 .

Table 1

Frequency by diagnosis made

\begin{tabular}{lc}
\hline Diagnosis* & Frequency \\
\hline Periorbital hematoma & 33 \\
Conjunctival hemorrhage & 14 \\
Corneal laceration & 6 \\
Orbital fracture & 5 \\
Eyebrow laceration & 5 \\
Eyelid laceration & 3 \\
Herniated iris & 3 \\
Laceration of conjunctiva & 3 \\
Hyphema & 2 \\
Without changes & 2 \\
Retinal detachment & 2 \\
Choroid detachment & 2 \\
Hypertensive uveitis & 1 \\
Laceration of sclera & 1 \\
Choroidal rupture & 1 \\
Retinal hemorrhage & 1 \\
Subgaleal hematoma & 1 \\
Vitreous hemorrhage & 1 \\
\hline
\end{tabular}

* The same patient may have more than one diagnosis.

\section{DisCusSION}

The present study showed that the prevalence of cases of emergency care due to fall from standing height in women is greater than in men. Such result is according to the CDC study of 2001.

In contrast to the result of the Guideline for the prevention of falls in the elderly of 2001 of the American Geriatrics Society, the British Geriatrics Society ${ }^{(6)}$ and a panel of prevention of falls of the American Academy of Orthopedic Surgeons, which accounted for only $5 \%$ of hospitalization due to falls in elderly, the present study examined a percentage of $17.3 \%$ hospitalizations. This fact proves that when there is eye trauma in falls from standing height in elderly, morbidity increases exponentially.
Other data obtained from this study is the fact that the cases assessed of ocular traumas from fall from standing height in men have more severe consequences than in women, since in $42.1 \%$ of cases in men hospitalization with subsequent reconstructive surgery was required, whereas in women this percentage was $30.3 \%$. In this sense, the percentage of sequelae was also higher in the case of men, reaching $26.3 \%$ in contrast to $18.1 \%$ in women.

One should pay attention to the possibility that men and women have similar prevalence of falls, but women seek more care than men, whi end up doing it only in cases of greater severity. This way, it would explain the fact that the results of the study show the cases of fall from standing height in men resulting in more hospitalizations, surgeries and visual sequelae than in women.

Of the 18 surgical cases, half got some visual sequelae, a number that expresses the complexity of the surgery from this type of trauma.

Of the cases in which there were sequelae, $100 \%$ underwent hospitalization.

As an addendum to this discussion there are two extremely important issues regarding falls in the elderly:

\section{Risk factors:}

When addressing an issue as falls in the elderly, it is important to address the risk factors for such events, given the severity of injuries that can occur and the possibility of intervention to reduce the prevalence of trauma.

Different risk factors are found in different studies due to the multifactorial nature of falls. The biggest risk factors identified are: gait/balance, medication, orthostatic hypotension, visual and cognitive impairments. Impaired gait and balance, followed by medication, were the most relevant risk factors.

The place of fall, whether indoors or outdoors, must also be considered in the identification of risk factors. Studies have suggested that indoor falls tend to happen to more fragile people, and outdoor falls tend to happen in younger and more active people. ${ }^{(7,8)}$ This way, strategic measures for preventing falls are different according to the place of the fall.

Even if some falls happen to individuals with no risk factors, the risk for falling increases according to the amount of risk factors. ${ }^{(9-11)}$

It is estimated that the risk for falls is even bigger in patients newly hospitalized having other risk factors for falling. ${ }^{(12)}$

1) Postural control - the clinical measures to prevent falls in elderly require knowledge of age-related changes that affect the postural control and increase the risk for falls.

- Sensory systems: the ability to maintain upright position relies on sensory capabilities of different systems, including the visual, vestibular and proprioceptive ones. Declines in the three systems mentioned naturally happen with aging.

- Visual difficulties result from decreased visual acuity, depth perception, sensitivity to contrast and adaptation to darkness. ${ }^{(13)}$ The use of multifocal lenses also increase the risk for falls. ${ }^{(14)}$

- The loss of proprioceptive sensitivity happens in the lower extremities and allows an increased risk for falls. ${ }^{(15)}$

- The vestibular system is reduced by the loss of labyrinthine ciliary cells, vestibular ganglion cells and nerve fibers.

- Hearing loss is also associated to increased risk for falls, but it is uncertain if this is a concurrent vestibular dysfunction or an independent risk factor for falls. ${ }^{(16)}$ 
- Muscle composition and activation - one of the most important differences in the postural control between a youngster and an elderly is related to muscle activation patterns.

2) History of falls - previous history of falls is a significant risk factor for new falls. ${ }^{(17-19)}$

3) Blood pressure - regulation of systemic blood pressure is a major contributor to the maintenance of upright posture. ${ }^{(20)}$ Postural hypotension may trigger failure in the cerebral perfusion by increasing the risk for falls.

4) Chronic diseases - several age-related chronic diseases are associated to increased risk for falls.

- Parkinson's disease increases the risk for falls via several mechanisms: stiffness in the extreme lower muscles, inability to correct trajectory deviations due to the slowness in initiating movement, hypotensive effects of drugs and, in some cases, cognitive impairments. ${ }^{(21)}$

- Chronic pain in the musculoskeletal system increases the risk for falls, and the risk is related to the severity of the pain and the number of regions involved. ${ }^{(22)}$

- Osteoarthritis in the knee affects mobility and ability to maneuver and overcome obstacles and postural stability due to the tendency to avoid overloading the leg with the pathology. Chronic pain can also interfere with attention and cognitive reaction, leading to the fall.

- Falling rates are greater in elderly individuals with diabetes when compared to individuals without diabetes. ${ }^{(23)}$

The risk for falls increases with the amount of chronic diseases.

5) Cognitive impairments - discrete to moderate cognitive impairments are associated to the risk for falls.

Anatomical changes associated to cognitive impairments are also correlated to the risk for falls. A prospective study demonstrated that the volume of lesions in the white matter of the brain cortex is directly associated to the risk for falls. ${ }^{(24)}$

There is evidence that a better social integration with family and friends can reduce the risk for falls in the elderly. ${ }^{(25)}$

6) Use of medication - it is one of the risk factors for falls.

A large number of medications of the same class, recent changes in dosage and low adherence to the use of medications are risk factors for falls. ${ }^{(26)}$

- Drugs that affect the central nervous system (CNS) drugs as neuroleptics, benzodiazepines and antidepressants seem to be the drugs most commonly associated to falls. ${ }^{(27-31)}$ It is still not known if the risk for falls is related to the onset of antidepressant drugs and titration or to stable chronic use.

- Anti-hypertensive and cardiovascular medications vasodilators and diuretics are associated to increased risk for falls. ${ }^{(32,33)}$

7) Alcohol intake - the relationship between alcohol use and the incidence of falls depends on the amount of alcohol consumed. In a study with men aged 65 or older, light alcohol drinkers (less than 14 drinks per week) had at least two times lower risk for falls compared to abstainers. ${ }^{(34)}$ However, men with serious alcohol-related problems had twice or more risk for falls compared to those who do not have drinking problem.

8) Shoes - they can be an important factor related to the risk for falls. In a small study evaluating balance and footwear in elderly men showed that thin and hard soles are associated with a greater balance in these shoes but such was perceived comfort worse than in those with thick soles and soft as running shoes. ${ }^{(35)}$ In contrast to this laboratory study, in another study with control case we found lower risk for falls associated to the use of athletic shoes (or sneakers) and a higher risk for falls with other types of shoes. Walking barefoot represents a risk for falls. ${ }^{(36)}$

Given the conflicting studies, it is still uncertain what type of footwear promotes the lower risk for falls. However, shoes without high heels are undeniably recommended.

9) Environmental factors - they often interact with the intrinsic risk factors, thus their relative importance to falls is clearly estimated.

Anyway, attention to home safety measures are recommended.

Falls in hospitals or nursing homes happen more frequently and are associated to higher morbidity than falls in the community. ${ }^{(37)}$

Men and women over 65 years with low serum dosage of 25-hydroxyvitamin D have a higher risk for loss of strength and muscle mass. ${ }^{(38)}$ Serum concentrations below $20 \mathrm{mg} / \mathrm{ml}$ are also associated to poorer physical performance and performance decline in male and female elderly. ${ }^{(39)}$

\section{II. "Fear of falling":}

The fear of falling, also called post fall anxiety syndrome, is a syndrome recognized in elderly. In a study conducted with a sample of more than a thousand women between 70 and 85 years of age, the fear of falling, determined by questionnaire, was found in at least one third of women and affected $46 \%$ of this sample in the subsequent 3 years. ${ }^{(40)}$

In another study with 673 elderly, $60 \%$ reported moderate restriction of activities, and $15 \%$ significant restriction of activities due to the fear of falling. ${ }^{(41)}$

The fear of falling was associated to: living alone; cognitive, balance and mobility impairment; depression; and previous history of falls. ${ }^{(40,42)}$

\section{Conclusion}

Eye injuries from falls from standing height are important not only for its severity, but also due to obtaining preventive measures from the knowledge of their risk factors.

After analyzing the data collected, this study allowed the assessment of a higher prevalence of attendances from fall from standing height in women compared to men. And in the latter, the severity of cases was reasonably higher.

Ophthalmologists should be aware of these risk factors so that they can identify the cause of the fall and guide the patient and their family for prevention.

\section{REFERENCES}

1. King MB, Tinetti ME. Falls in community-dwelling older persons. J Am Geriatr Soc 1995; 43(10):1146-54.

2. Tinetti ME, Speechley M, Ginter SF. Risk factors for falls among elderly persons living in the community. N England J Med. 1988; 319(26):1701-7.

3. Chang JT, Morton SC, Rubenstein LZ, Mojica WA, Maglione M, Suttorp MJ, et al. Interventions for the prevention of falls in older adults: systematic review and meta-analysis of randomized clinical trials. BMJ. 2004: 328(7441):608.

4. Centers for Disease Control and Prevention (CDC). Public health and aging: nonfatal injuries among older adults treates in hospital emergency departaments - United States, 2201. MMWR Morb Mortal Wkly Rep. 2003; 52(42):1019-22. 
5. Thapa PB, Brockman KG, Gideon P, Fought RL, Ray WA. Injurious falls in nonambulatory nursing home residents: a comparative study of circumstances, incidence, and risc factors. J Am Geriatr Soc. 1996; 44(3):273-8.

6. Guideline for the prevention of falls in older persons. American Geriatrics Society, British Geriatrics Society, and American Academy of Orthopaedic Surgeons Panel on Falls Prevention. J Am Geriatr Soc. 2001; 49(5):664-72.

7. Bergland A, Jarnlo GB, Laake K. Predictors of falls in the elderly by location. Aging Clin Exp Res. 2003; 15(10:43-50.

8. Bath PA, Morgan K. Differential risk factor profiles for indoor and outdoor falls in older people living at home in Nottingham, UK. Eur J Epidemiol. 1999; 15(1):65-73.

9. Nevitt MC, Cummings SR, Hudes ES. Risk factors for injurious falls: a prospective study. J Gerontol. 1991;45(6):M164-70.

10. Tinetti ME, Speechley M, Ginter SF. Risk factors for falls among elderly persons living in the community. N England J Med 1988; 319(26):1701-7.

11. Campbell AJ, Borrie MJ, Spears GF, Risk factors for falls in a community-based prospective study of people 70 years and older. J Gerontol. 1989; 44:M112.

12. Mahoney JE, Palta M, Johnson J, Jalalluddin M, Gray S, Park S, et al. Temporal association between hospitalization and rate of falls after discharge. Arch Intern Med. 2000; 160(18):2788-95.

13. Lord SR, Dayhew J. Visual risk factors for falls in older people. J Am Geriatr Soc. 2001; 49(5):508-15.

14. Lord SR, Dayhew J, Howland A. Multifocal glasses impair edgecontrast sensitivity and depth perception and increase the risk of falls in older people. J Am Geriatr Soc. 2002; 50(11):1760-6.

15. Richardson JK, Hurvitz EA. Peripheral neuropathy: a true risk factor for falls. J Gerontol A Biol Sci Med Sci. 1995; 50:M211.

16. Viljanen A, Kaprio J, Pyykkö I, Sorri M, Pajala S, Kauppinen M, et al. Hearing as a predictor of falls and postural balance in older female twins. J Gerontol A Biol Sci Med Sci. 2009; 64(2):312-7.

17. Nevitt MC, Cummings SR, Kidd S, Black D. Risk factors for recurrent nonsyncopal falls. A prospective study. JAMA. 1989; 261(18):2663-8

18. Teno J, Kiel DP, Mor V. Multiple stumbles: a risk factor for falls in community-dwelling elderly. A prospective study. J Am Geriatr Soc. 1990; 38(12):1321-5.

19. Kiely DK, Kiel DP, Burrows AB, Lipsitz LA. Identifying nursing home residents at risk for falling. J Am Geriatr Soc. 1998; 46(5):551-5.

20. Kario K, Tobin JN, Wolfson LI, Whipple R, Derby CA, Singh D, et al. Lower standing systolic blood pressure as a predictor of falls in the elderly: a community-based prospective study. J Am Coll Cardiol. 2001; 38(1):246-52.

21. Wood BH, Bilclough JA, Bowron A, Walker RW. Incidence and prediction of falls in Parkinson's disease: a prospective multidisciplinary study. J Neurol Neurosurg Psychiatry. 2002; 72)6):721-5

22. Leveille SG, Jones RN, Kiely DK, Hausdorff JM, ShmerlingRH, Guralnik JM, et al. Chronic musculoskeletal pain and the occurrence of falls in an older population. JAMA. 2009; 302(20):2214-21.

23. Schwartz AV, Hillier TA, Sellmeyer DE, Resnick HE, Gregg E, Ensrud KE, et al. Older women with diabetes have a higher risk of falls: a prospective study. Diabetes Care. 2002; 25(10):1749-54.

24. Srikanth V, Beare R, Blizzard L, Phan T, Stapleton J, Chen J, et al. Cerebral white matter lesions, gait, and the risk of incident falls: a prospective population-based study. Stroke. 2009; 40(1):175-80.

25. Faulkner KA, Cauley JA, Zmuda JM, Griffin JM, Nevitt MC. Is social integration associated with the risk of falling in older community-dwelling women? J Gerontol A Biol Sci Med Sci. 2003; 58:M954.
26. Berry SD, Quach L, Procter-Gray E, Kiel DP, Li W, Samelson EJ, et al. Poor adherence to medications may be associated with falls. J Gerontol A Biol Sci Med Sci. 2010; 65(5):553-8.

27. Lawlor DA, Patel R, Ebrahim S. Association between falls in elderly women and chronic diseases and drug use: cross sectional study. BMJ. 2003; 327(7417):712-7.

28. Ray WA, Griffin MR, Schaffner W, et al. Psychotropic drug use and the risk of hip fracture. N Engl J Med. 1987;316(7):363-9.

29. Ray WA, Griffin MR, Malcolm E. Cyclic antidepressants and the risk of hip fracture. Arch Intern Med. 1991;151(4):754-6.

30. Ray WA, Griffin MR, Downey W. Benzodiazepines of long and short elimination half-life and the risk of hip fracture. JAMA. 1989; 262(23):3303-7.

31. Ensrud KE, Blackwell TL, Mangione CM, Bowman PJ, Whooley MA, Bauer DC, et al. Central nervous system-active medications and risk for falls in older women. J Am Geriatr Soc. 2002; 50(10):1629-37.

32. Myers AH, Baker SP, Van Natta ML, Abbey H, Robinson EG. Risk factors associated with falls and injuries among elderly institutionalized persons. Am J Epidemiol. 1991; 133(11):1179-90.

33. Cawthon PM, Harrison SL, Barrett-Connor E, Fink A, Cauley JA, Lewis CE, et al. Alcohol intake and its relationship with bone mineral density, falls, and fracture risk in older men. J Am Geriatr Soc. 2006; 54(11):1649-57.

34. Robbins S, Gouw GJ, McClaran J. Shoe sole thickness and hardness influence balance in older men. J Am Geriatr Soc. 1992; 40(11):1089-94.

35. Koepsell TD, Wolf ME, Buchner DM, Kukull WA, LaCroix AZ, Tencer AF, et al. Footwear style and risk of falls in older adults. J Am Geriatr Soc. 2004; 52(9):1495-501.

36. Leland NE, Gozalo P, Teno J, Mor V. Falls in newly admitted nursing home residents: a national study. J Am Geriatr Soc. 2012; 60(5):939-45.

37. Visser M, Deeg DJ, Lips P, Longitudinal Aging Study Amsterdam. Low vitamin D and high parathyroid hormone levels as determinants of loss of muscle strength and muscle mass (sarcopenia): the Longitudinal Aging Study Amsterdam. J Clin Endocrinol Metab. 2003; 88(12):5766-72.

38. Wicherts IS, van Schoor NM, Boeke AJ, et al. Vitamin D status predicts physical performance and its decline in older persons. J Clin Endocrinol Metab. 2007; 92(6):2058-65.

39. Austin N, Devine A, Dick I, Prince R, Bruce D. Fear od falling in older woman: a longitudinal study of incidence, persistence, and predictor. J Am Geriatr Soc. 2007; 55(1):1598-603.

40. Deshpande N, Metter EJ, Laurentani F, Bandinelli S, Guralnik J, Ferrucci L. Activity restriction induced by fear of falling and objective and subjective measures of physical function: a prospective cohort study. J AM Geriatr Soc. 2008: 56(4): 615-20.

41. Tinetti ME, Mendes de Leon CF, Doucette JT, Baker DI. Fear of falling and fall-related efficacy in relationship to functioning among community-living elders. J Gerontol. 1994; 49(3):M140

\author{
Corresponding author: \\ Daniel Zaide Spritzer \\ Av. Pasteur, 72, Botafogo, Rio de Janeiro, RJ, Brazil \\ ZIP Code 22290-240 \\ Fax: (21) 2244-6395 \\ E-mail: danielzaide@gmail.com
}

